\title{
\#FeesMustFall2016: Perceived and measured effect on clinical medical students
}

\author{
H Brits, ${ }^{1}$ MB ChB, MFamMed, MHPE; G Joubert, ${ }^{2}$ BA, MSc; L Lomberg, ${ }^{1}$ 2nd-year medical student; \\ P Djan, ${ }^{1}$ 2nd-year medical student; G Makoro, ${ }^{1}$ 2nd-year medical student; M Mokoena, ${ }^{1}$ 2nd-year medical student; \\ P Malate, ${ }^{1}$ 2nd-year medical student; D Tengu, ${ }^{1}$ 2nd-year medical student \\ ${ }^{1}$ Department of Family Medicine, Faculty of Health Sciences, University of the Free State, Bloemfontein, South Africa
${ }^{2}$ Department of Biostatistics, Faculty of Health Sciences, University of the Free State, Bloemfontein, South Africa
}

Corresponding author: H Brits (britsh@ufs.ac.za)

\begin{abstract}
Background. Medical students are under immense academic stress. Campus unrest can contribute to stress and influence academic performance, social behaviour, emotional stability and financial expenses.

Objectives. To investigate the effects of \#FeesMustFall2016 (\#FMF2016) on the 2016 3rd-year (semester 6) clinical medical students at the University of the Free State (UFS), Bloemfontein, South Africa.

Methods. In phase 1 of the project, anonymous questionnaires were completed by the clinical students who experienced physical test disruption during \#FMF2016. Opinions regarding academic performance, financial expenses, behaviour changes and stress levels were gathered. The students also completed a formal post-traumatic stress screening assessment. In phase 2 of the project, the academic performance of these students was compared with that of students not affected by \#FMF2016.

Results. Of the target population of 138 students, $87.0 \%$ completed the questionnaires. Three-quarters of the respondents reported a negative effect on academic performance, and most did not believe that the delivering of lectures on Blackboard was a good way of training Alcohol consumption increased in $31.9 \%$ of the students. Criteria for post-traumatic stress disorder (PTSD) were met in $12.7 \%$ of students. Compared with previous and later cohorts of students there were no clear differences regarding marks, but there was a tendency towards poorer performance and more failures the next year.

Conclusions. Semester 6 medical students at UFS reported that the \#FMF2016 protests had a negative effect on academic, social, financial and stress aspects. PTSD was present in $12.7 \%$ of students compared with $7.8 \%$ in similar populations.
\end{abstract}

S Afr Med J 2019;109(7):493-497. DOI:10.7196/SAMJ.2019.v109i7.13686

Medical school is a highly competitive and stressful environment for most medical students. ${ }^{[1]}$ The prevalence of stress experienced by medical students has been reported to vary between $41.9 \%$ and $63.7 \%$ in different parts of the world. ${ }^{[2-4]}$ Two South African (SA) studies reported stress levels as high as $78 \%$ among medical students. ${ }^{[5,6]}$ Information overload, lack of holidays, difficulty with transport to training sites, and socially related factors in the clinical environment are some of the issues that contribute to the stress experienced by medical students. ${ }^{[2,7,8]}$ It is therefore not surprising that studies have found medical students to be more distressed than students in any other undergraduate course. ${ }^{[2,3]}$

The effect of added external stress on already high levels of stress is unpredictable..$^{[9]}$ It can be expected that added uncontrollable external stress may have negative effects on already stressed individuals such as medical students. The September/October 2016 \#FeesMustFall (\#FMF2016) protests caused disruption to the academic curriculum of most SA universities, including the University of the Free State (UFS). ${ }^{[10]}$

Student protests regarding high education fees started at Fort Hare University and the Cape Peninsula University of Technology as long ago as 1994. However, owing to their small scale, these protests did not make headline news. ${ }^{[11]}$ In October 2015, student protests started at the University of the Witwatersrand, spreading to the University of Cape Town and Rhodes University, and subsequently to most universities in SA. After government intervention, the protests stopped for a while. ${ }^{[12]}$ However, in mid-August 2016, the Minister of Higher Education announced a maximum fee increase of $8 \%$ for universities. Within days, students at most universities participated in the \#FMF2016 campaign. ${ }^{[13]}$ \#FMF2016 resulted in violent protests and the eventual closure of most SA universities towards the end of 2016. ${ }^{[14]}$

University strikes are common at Canadian universities. ${ }^{[15-18]} \mathrm{A}$ study at York University in Toronto emphasised the negative effects that student protests had on the students in general. ${ }^{[15]}$ The study used self-administered questionnaires to collect data from students regarding academic performance and future plans, anxiety levels, available internet information and social behaviour during the strike. In conclusion, studies suggested that more research is needed on students' reactions to similar university crises and that universities should commit to maintaining informative websites to keep students informed. ${ }^{[15,16]}$ These studies all reported on student perceptions, and none of the claims was verified.

In $\mathrm{SA}$, labour protests are common and much information is available on the effect of protests on the economy. However, no studies could be found on the effect of university strikes on students. ${ }^{[19,20]}$ If more information is available, better planning and support can be offered to all affected parties during protests.

\section{Objectives}

To determine the perceptions and measured effect of the \#FMF2016 protest on the 2016 3rd-year (semester 6) undergraduate medical students at UFS who experienced physical test disruption and temporary interruption of classes and clinical training. Specific objectives were: ( $i$ ) to assess the perceptions of students regarding the 
effect of the protests on academic performance, social behaviour and financial implications; (ii) to assess students' perceptions regarding information sharing and support of authorities during the protest; (iii) to determine the presence of post-traumatic stress disorder (PTSD) after students experienced violent and physical test disruption, using a validated post-traumatic stress tool; and (iv) to measure the effect of \#FMF2016 on academic performance by comparing end-of-year examination marks with marks of students not affected by protests.

\section{Methods}

To address the study objectives, the project consisted of two phases. In phase 1, a descriptive study was performed to gather students' perceptions of the effect of \#FMF2016, and screening for PTSD took place. In phase 2, examination marks of students affected by \#FMF2016 were compared with marks of students not affected by \#FMF2016.

\section{Phase 1: Students' perceptions of the effect of \#FMF2016 and results of PTSD screening Study population and sampling}

The study population consisted of 138 medical students who were in their 3rd year in 2016 at the UFS Bloemfontein campus. This class was selected because they experienced physical test disruptions and violent behaviour at a university venue. The 4 th- and 5 th-year clinical students received most of their training at off-campus clinical sites and in small groups, and were therefore not affected as much by the \#FMF2016 unrest. The entire class was included, so no sampling method was required.

\section{Measurements}

The perceived effects of the protest were measured using voluntary, anonymous self-administered questionnaires. Completion of the questionnaires implied consent. The first part of the questionnaire gathered demographic information on age, gender, accommodation, and source of funding for the students' studies. This was followed by 25 statements on the perceived effect of the protests on academic performance, finances and social behaviour, as well as students' attitudes to the UFS management, the protest in general, and stress experienced. These questions were derived from the results and recommendations of the studies referenced at the beginning of the article. ${ }^{[15-18]}$ Students had four options for each statement, namely 'strongly disagree', 'disagree', 'agree' and 'strongly agree'. The last part of the questionnaire included a validated PTSD screening tool developed by Brewin et al. ${ }^{[21]}$ The screening tool consisted of 10 questions and, according to the instructions, a score of $\geq 6$ was considered positive for PTSD. The questionnaire was only available in English, as the Brewin questionnaire was only validated in English. Class group leaders distributed and collected the completed questionnaires. The study was performed in the second semester of 2017 after ethical and UFS permission had been obtained.

\section{Pilot study}

A pilot study was conducted to test the clarity and appropriateness of the questionnaire. Twenty 2017 3rd-year medical students filled in the questionnaire. Minor changes were made to improve the flow of the questionnaire.

\section{Data analysis}

Data were filled in on Excel 2016 spreadsheets (Microsoft, USA) and double-checked for errors. The Department of Biostatistics, Faculty of Health Sciences, summarised the data using frequencies and percentages (categorical variables) and mean (age). For analysis, the options 'strongly disagree' and 'disagree' were grouped, as were 'agree' and 'strongly agree. This was done because of the small numbers in many subcategories.

\section{Phase 2: Comparison of student marks}

Study population and sampling

The study population consisted of the 3rd-, 4th- and 5th-year medical students at UFS who took part in the end-of-year assessment during 2015, 2016 and 2017, respectively.

\section{Measurements}

As a first step, the mid-year 3rd-year examination marks of the student groups included in the study were compared to establish whether the groups were comparable. Secondly, the marks of the 2016 3rd-year students were then compared with the 3rd-year marks of the 2015 and 2017 students. The 4th-year marks of these students were also compared with the 4th-year marks of the 2015 and 2016 students. Finally, as the 2016 4th- and 5th-year students were also affected by the \#FMF2016 protests, their marks were compared with the students of 2015 and 2017.

After ethics committee and university authority approval, student marks, linked to student numbers, were obtained from the official database of the Faculty of Health Sciences. This is a secure database with password protection, and only authorised access is permitted.

\section{Pilot study}

No pilot study was conducted, as the specific data required and the data analysis were discussed with a biostatistician before the data gathering.

\section{Data analysis}

The data were available in Excel 2016 spreadsheets, and were sorted according to years and modules. The average mark and percentage of failures over all modules were calculated for each year group and then compared using $t$-tests (average marks) and Fisher's exact test (percentage of failures).

\section{Ethical considerations}

Ethical approval to conduct the study was obtained from the Health Sciences Research Ethics Committee of UFS (ref. no. HSREC-S 24/2017). Approval to include students and use student marks was granted by the appropriate authorities of UFS. No person was identified, as the questionnaires were anonymous and only student numbers were used for the mark comparison. A psychologist was available to assist students who experienced high levels of stress during questionnaire completion.

\section{Results \\ Phase 1: Students' perceptions of the effect of \#FMF2016 and results of PTSD screening}

A total of 120 students completed the questionnaire. The student response rate was $87.0 \%$, with an equal distribution between males and females. Student ages varied between 20 and 28 years, with a mean of 22 years. Before the protest, $22.2 \%$ of students lived on campus, which decreased to $7.5 \%$ after the protests.

The majority of the students used a combination of funding sources for their studies, with parents and family contributing in $>60 \%$ of cases. Fewer than $50 \%$ of students studied with some type of bursary. Only one student indicated that he/she received funding from the National Student Financial Aid Scheme. 
Most of the students (74.0\%) agreed that \#FMF2016 had a negative effect on academic performance (Fig. 1). Almost all the students (92.3\%) disagreed with the statement that they spent less money during the protests. Behaviour changed negatively, with $40.0 \%$ of students reporting changes in sleeping patterns and $31.9 \%$ reporting that they consumed more alcohol. Fig. 1 is a summary of some of their responses.

In general, students felt negative about the protests, with $79.7 \%$ fearing a reoccurrence the following year. Poor communication with students on the part of the authorities was claimed by $56.7 \%$ of students. Some of the general responses are summarised in Table 1.

The self-reported stress levels of the students were a median of 6 out of 10 during the protest and 5 out of 10 at the time of data collection (range 0 - 10 during both occasions). The largest percentage of students (42.5\%) reported higher levels of stress during the protest, followed by $29.2 \%$ who reported the same levels during the protest as currently experienced, and $28.3 \%$ who reported lower stress levels during the protest. Using the validated PTSD screening tool, $12.7 \%$ of students screened positive for PTSD.

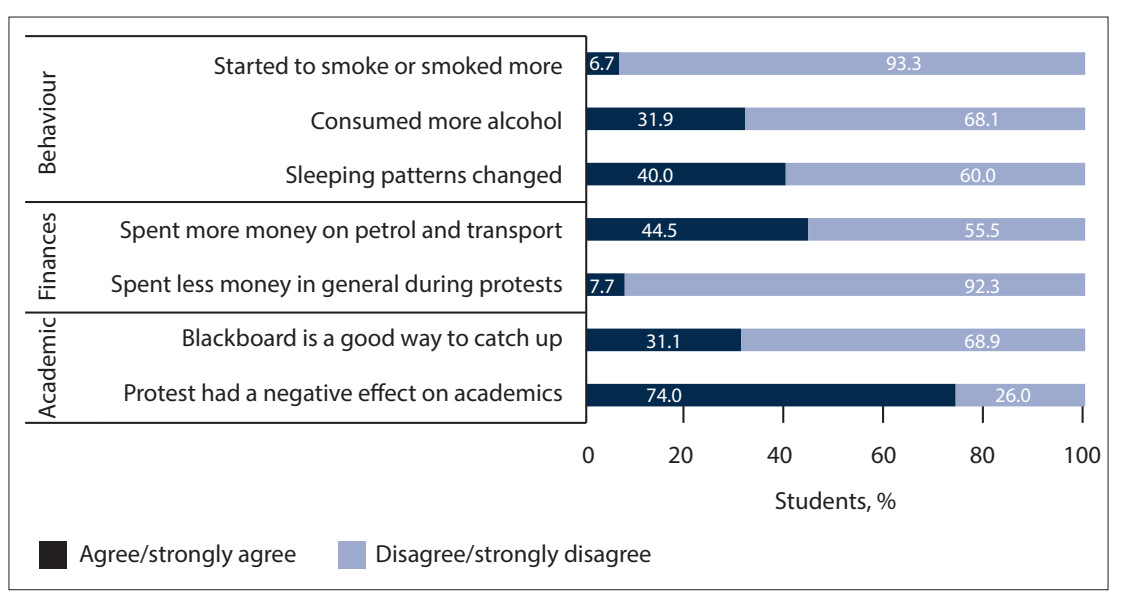

Fig. 1. The perceived effect of \#FMF2016 on student behaviour, finances and academic performance.

Table 1. Students' perceptions of some aspects of \#FMF2016

\begin{tabular}{ll}
\hline Student responses & $\%$ \\
\hline I felt safer with additional security present & 42.4 \\
I felt unsafe during the disruption of the test & 83.1 \\
I feared for reoccurrence of \#FMF in 2017 & 79.7 \\
I experienced physical intimidation during test disruption & 80.5 \\
I supported the cause of \#FMF & 39.5 \\
I felt pressurised to participate in protests & 29.2 \\
I partook in the protests & 5.8 \\
I felt angry towards the university for closing it & 54.2 \\
I felt that the faculty supported us well & 50.8 \\
\#FMF2016 = \#FeesMustFall2016. &
\end{tabular}

PTSD was slightly higher in female $(15.8 \%)$ than male students $(10.0 \%)(p=0.35)$. Male students were significantly more likely to agree that they consumed more alcohol during the protest $(43.3 \%)$ than female students $(20.3 \%)(p=0.01)$. Female students were more likely to have supported the cause of the protest $(47.5 \%)$ than male students $(30.5 \%)(p=0.06)$, but more males (33.3\% v. $25.4 \%$ of females; $p=0.34$ ) reported having felt pressurised to join the protest. Only $3.3 \%$ of males indicated that they had participated in the protest, compared with $8.5 \%$ of female students $(p=0.27)$. No significant differences were found between age groups $(<23 ; \geq 23$ years) with regard to these variables.

\section{Phase 2: Comparison of student marks}

The average entry marks into the clinical phase of the study for the different year groups used in the study were $63.6 \%$ (2014), $70.1 \%$ (2015), $65.4 \%$ (2016) and 63.1\% (2017). There was no statistically significant difference between the groups, and the groups were considered comparable.

The 2016 3rd-year class experienced the physical test disruption; however, all 2016 


\begin{tabular}{|c|c|c|c|c|}
\hline Year group & 2015 & 2016 & 2017 & $p$-value \\
\hline \multicolumn{5}{|l|}{ 3rd-years } \\
\hline Mean (\%) & 64.4 & 63.2 & 64.7 & 0.10 \\
\hline Failure (\%) & 5.2 & 6.7 & 3.4 & 0.69 \\
\hline \multicolumn{5}{|l|}{4 th-years } \\
\hline Mean (\%) & 67.3 & 68.0 & 67.1 & 0.37 \\
\hline Failure (\%) & 1.9 & 1.9 & 5.9 & 0.14 \\
\hline \multicolumn{5}{|l|}{ 5th-years } \\
\hline Mean (\%) & 68.2 & 67.9 & 69.7 & 0.07 \\
\hline Failure (\%) & 2.9 & 1.9 & 2.0 & 0.90 \\
\hline
\end{tabular}

Blackboard was also used for communication with students, and more than half of the students felt that the communication was not good. Lack of internet access may have been a factor contributing to this opinion. Canadian studies also found that lack of internet access played a role in student dissatisfaction during strikes, but suggested that communication with students should be through the official communication networks of the university, ${ }^{[15-18]}$ which is currently Blackboard for UFS.

Although the protests did not have a major effect on smoking, a third of the students confessed to consuming more alcohol and $40.0 \%$ experienced changes in sleeping patterns. Both alcohol consumption and changes in sleeping patterns can have negative effects on academic performance, through the direct effect on memory, decreased motivation and less time to spend on studies. ${ }^{[22-24]}$ Behaviour changes during protests are not unique to our setting, as various studies have reported that protests contributed to behaviour changes and increases in alcohol consumption. ${ }^{[15-18]}$ Higher alcohol consumption may also contribute to increased financial expenditure.

Only half of the students felt that the faculty supported them during the protests. This phenomenon of students feeling unsupported by authorities or universities has also been found in other studies. ${ }^{[16-18]}$ Students felt stressed, with $79.7 \%$ fearing reoccurrence of protests. Despite the protests, stress levels never increased to abnormally high levels. It is difficult to compare stress levels between studies, as different measures were used to assess stress. Self-reported stress in a study at the University of KwaZulu-Natal was $78 \%$ among medical students, while a study in Pakistan reported moderate stress in 71.7\% of medical students and high levels of stress in $20.8 \%$. Both these studies were done under usual conditions. ${ }^{[6,25]}$ A study at UFS found that $46.1 \%$ of 4 th-year medical students suffered from burnout, which may be an indication of high stress levels in this setting. ${ }^{[26]}$ The 2016 semester 6 students were assessed in 2015 (in semester 3) and according to the Depression Anxiety Stress Scales (DASS-21), 35.0\% of them screened positive for stress. ${ }^{[27]}$

Using a validated PTSD screening tool, ${ }^{[21]} 12.7 \%$ of the 120 students screened positive for PTSD after the test disruption. This is much higher than the global figures of $7.8-9.2 \%$ found in similar populations exposed to a traumatic event. ${ }^{[28]}$

No negative effect of the protests could be demonstrated from the student marks, although $74.0 \%$ of students felt that the protests had a negative effect on academic performance. A negative effect on academic performance has been reported in other studies, but all were self-reported views. ${ }^{[15-18]}$ Stress does not necessarily affect cognition negatively, and academic performance may even improve with moderate added stress. ${ }^{[9,29]}$

Although \#FMF2016 did not have a negative effect on academic performance, PTSD and increased alcohol consumption may have long-term effects on individuals in this already stressful environment.

\section{Study limitations}

The data collection on student perceptions of \#FMF2016 only took place during 2017, as the students left for their holiday after the examination, and the study could only be conducted after ethical approval and granting of permission by the authorities.

\section{Conclusions}

From the data collected and interpretation thereof, it was possible to report on the perceived and real effect of \#FMF2016 on clinical medical students at UFS. These results may also be generalisable to other medical faculties, as their students experience the same study and environmental stress. The negative coping mechanisms displayed in this study may assist medical faculties to prepare students for additional stress and equip them to cope with it. Contingency plans to communicate effectively with students and staff during unforeseen student unrest need to be in place and tested.

Reported negative behaviour changes occurred, with 31.9\% of students reporting increased alcohol consumption and $40.0 \%$ reporting changes in sleep patterns. Both these factors may have a negative effect on academic performance, although it was not demonstrated.

The financial burden on the students increased, with transport a major contributor and relocation to off-campus accommodation another possible factor. This extra expense placed additional stress on the already financially strained students.

Only half of the students felt that the university supported them sufficiently and that communication was adequate, despite regular updates on Blackboard, the official communication medium for the students.

The general stress levels of the students were not abnormally high, but $79.7 \%$ feared reoccurrence of the protests. Alarmingly, however, $12.7 \%$ of students screened positive for PTSD after the violent test disruption.

Although $74.0 \%$ of students claimed poorer academic performance due to the protests, this could not be proved by comparing examination results with those of students not affected by protests.

\section{Recommendations}

- Owing to the lack of local data, a study to determine the general stress levels of medical students, as well as PTSD, in our study population will be valuable.

- The high prevalence of PTSD in our study population warranted the subsequent appointment of a clinical psychologist and a social worker to assist medical students in coping. 
- Feedback of the results should be made available to the faculty and university authorities.

- Recommendations from this and other studies are to improve communication during protests and to keep students informed via official university networks. Attention should be paid to improving internet access from off-campus sites.

\section{Declaration. None.}

Acknowledgements. The authors thank the clinical psychologist for making herself available to support students during the project, the students for participating in the project, and Ms T Mulder, medical editor, Office of the Dean, Faculty of Health Sciences, UFS, for technical and editorial preparation of the manuscript.

Author contributions. HB was the study leader who suggested the topic, supervised the students through phase 1 of the project process, and wrote the protocol for phase 2. GJ advised with the planning of the study, performed the analysis, assisted with the write-up of the manuscript, and was actively involved with the planning of phase 2. LL, PD, GM, MM, PM and DT, who were 2nd-year medical students at the time of the study, compiled the protocol for phase 1, performed the data collection and wrote the first draft report.

Funding. None.

Conflicts of interest. None.

1. Abdulghani HM, AlKanhal AA, Mahmoud ES, Ponnamperuma GG, Alfaris EA. Stress and its effects on medical students: A cross-sectional study at a college of medicine in Saudi Arabia. J Health Popul Nutr 2011;29(5):516-522. https://doi.org/10.3329/jhpn.v29i5.8906

2. Sherina MS, Rampal L, Kaneson N. Psychological stress among undergraduate medical students. Med J Malaysia 2004;59(2):207-211.

3. Haldorsen H, Bak NH, Dissing A, Petersson B. Stress and symptoms of depression among medical students at the University of Copenhagen. Scand J Public Health 2014;42(1):89-95. https://doi. org/10.1177/1403494813503055

4. Saipanish R. Stress among medical students in a Thai medical school. Med Teach 2003;25(5):502-506. https://doi.org/10.1080/0142159031000136716

5. Wilson DA, Warton C, Louw GJ. Stress, anxiety and academic performance among medical students at the University of Cape Town. S Afr J Child Adolesc Mental Health 1998;10(1):23-31. https://doi.or g/10.1080/16826108.1998.9632343

6. Naidoo SS, van Wyk J, Higgins-Opitz SB, Moodley K. An evaluation of stress in medical students at a South African university. S Afr Fam Pract 2014;56(5):258-262. https://doi.org/10.1080/20786190.
a a South Afric
2014.980157

7. Oku AO, Owoaje ET, Oku OO, Ikpeme BM. Prevalence of stress, stressors and coping strategies among medical students in a Nigerian medical school. Afr J Med Health Sci 2015;14(1):29-34. https://doi. org/10.4103/2384-5589.153384
8. Gupta S, Choudhury S, Das M, Mondol A, Pradhan R. Factors causing stress among students of a medical college in Kolkata, India. Educ Health (Abingdon) 2015;28(1):92-95. https://doi. of a medical college in Kolk

9. Sandi C. Stress and cognition. Wiley Interdiscip Rev Cogn Sci 2013;4(3):245-261. https://doi. 9. Sandi C. Stress and
org/10.1002/wcs.1222

10. Tandwa L. University students to protest against fee increases. News24. 21 October 2015. http:// Tandwa L. University students to protest against fee increases. News24. 21 October 2015. http://
www.news24.com/SouthAfrica/News/University-students-protest-against-fee-increases-20151021 (accessed 25 March 2017)

11. Davids N, Waghid Y. \#FeesMustFall: history of South African student protests reflects inequality's grip. Mail \& Guardian. 10 October 2016. https://mg.co.za/article/2016-10-10-feesmustfall-history-of south-african-student-protests-reflects-inequalitys-grip (accessed 25 March 2017).

12. Kekana M, Isaacs L, Corke E. Tuition fee protest shut down 2 of South Africa’s biggest universities. Eyewitness News. 19 October 2015. http://ewn.co.za/2015/10/19/Fee-protests-shuts-down-3-of-SAsbiggest-universities (accessed 25 March 2017).

13. Nicolson G. Fees Must Fall, reloaded. Daily Maverick. 12 January 2016. https://www.dailymaverick. co.za/article/2016-01-12-fees-must-fall-reloaded/ (accessed 25 March 2017).

14. The Daily Vox. Special editorial: The state of Fees Must Fall - 2016 edition. 19 October 2016. http:// www.thedailyvox.co.za/special-editorial-state-fees-must-fall-2016-edition/ (accessed 25 March 2017).

15. Wickens CM, Fiksenbaum LM, Greenglass ER, Wiesenthal DL. Student stress and coping following Wickens CM, Fiksenbaum LM, Greenglass ER, Wiesenthal DL. Student stress and coping following
a university strike in Canada. J Collect Negotiations 2006;31(1):1-19. https://doi.org/10.2190/2NU6a university strike in

16. Fiksenbaum LM, Wickens CM, Greenglass ER, Wiesenthal DL. Students' perceptions of fairness following an academic strike. Can J Higher Educ 2012;42(3):24-44.

17. Amos M, Day VH, Power E. Student reactions to a faculty strike. Can J Higher Educ 1993;23(2):86-103

18. Albas D, Albas C. Tertius dolens: The student experience of the University of Manitoba Faculty Association strike. Can Rev Sociol Anthropol 2000;37(4):461-483. https://doi.org/10.1111/j.1755618X.2000.tb00598.X

19. Bhorat H, Yu D, Khan S, Thorton S. Examination of the Impact of Strikes on the South African Economy. Cape Town: The Mandela Initiative, 2017. http://www.mandelainitiative.org.za/the-impactof-strikes.html (accessed 12 March 2018).

20. UKEssays. Positive and negative impacts of economic growth. 2013. https://www.ukessays.com/ essays/economics/positive-and-negative-impacts-of-economic-growth-economics-essay.php?vref=1 (accessed 12 March 2018).

21. Brewin CR, Rose S, Andrews B, et al. Brief screening instrument for post-traumatic stress disorder. Br J Psychiatry 2002;181(2):158-162. https://doi.org/10.1017/S0007125000161896

22. Onyebuchukwu JI, Muyiwa Adeniyi Sholarin MA, Emerenwa ABC. The effect of alcohol consumption Onyebuchukwu I, Muyiwa Adeniyi Sholarin MA, Emerenwa ABC. The effect of alcohol consumption
on the academic performance of undergraduate students. Psychol Behav Sci 2015;4(4):147-153. on the academic performance of undergr
https://doi.org/10.11648/j.pbs.20150404.12

23. El Ansari W, Stock C, Mills C. Is alcohol consumption associated with poor academic achievement in university students? Int J Prev Med 2013;4(10):1175-1188.

24. Porter SR, Pryor J. The effects of heavy episodic alcohol use on student engagement, academic performance, and time use. J Coll Stud Dev 2007;48(4):455-467. https://doi.org/10.1353/csd.2007.0042 25. Sohail N. Stress and academic performance among medical students. J Coll Physicians Surg Pak 2013;23(1):67-71

26. Colby L, Mareka M, Pillay S, et al. The association between the levels of burnout and quality of life among fourth-year medical students at the University of the Free State. S Afr J Psychiatry 2018;24(0):a1101. https://doi.org/10.4102/sajpsychiatry.v24i0.1101

27. Van Zyl PM, Joubert G, Bowen E, et al. Depression, anxiety, stress and substance use in medical students in a 5-year curriculum. Afr J Health Prof Educ 2017;9(2):67-72.

28. Atwoli L, Stein DJ, Koenen KC, McLaughlin KA. Epidemiology of posttraumatic stress disorder Atwoli L, Stein DJ, Koenen KC, McLaughlin KA. Epidemiology of posttraumatic stress disorder
prevalence, correlates and consequences. Curr Opin Psychiatry 2015;28(4):307-311. https://doi. org/10.1097/YCO.0000000000000167

29. Wu J, Yan J. Editorial: Stress and cognition. Front Psychol 2017;8:970. https://doi.org/10.3389/ fpsyg.2017.00970

Accepted 7 January 2019 